\title{
POTENSI MODAL PETANI DALAM MELAKUKAN PEREMAJAAN KARET DI KABUPATEN MUSI RAWAS SUMATERA SELATAN
}

\author{
(FARMER CAPITAL POTENCIES FOR REPLANTING RUBBER \\ PLANTATION IN MUSI RAWAS REGENCY SOUTH SUMATERA)
}

\author{
Maya Riantini \\ Jurusan Sosial Ekonomi Pertanian \\ Fakultas Pertanian Universitas Lampung \\ Email: mayaunila@yahoo.com
}

\begin{abstract}
The research aims to estimate capital potencies owned by farmer for replanting their rubber plantation and optimum land size for replanting in order to get continuous income. The research was conducted in Kelurahan Muara Beliti market, Pedang Village and Muara Beliti Village, Muara Beliti Subdistrict, Musi Rawas Regency. These research area were chosen purposively. Using a survey approach, sisty farmers are selcted randomly using Proportionate Stratified Random Sampling and interviewed. The data were collected from March to April 2008. The resusearch result showed thatPotential Capital owned by farmer was Rp. 2,693,350.00 plus Rp. 5,000,00.00 as an income from selling old rubber wood so that total capital owned by farmer was $R p$. 7,693,650. From the result of analysis using Linier Programming found that the optimum replanting area of rubber was 1,883 hectare with the income of Rp. 69.351.000. Meanwhile the human resources that were rarely found was family labor in which every unit addition of HOK will add the income of $R p .117,000$.

Keywords: farmers' capital, replanting, rubber plantation, potencies
\end{abstract}

\section{PENDAHULUAN}

Karet merupakan salah satu komoditi perkebunan penting, baik sebagai sumber pendapatan, kesempatan kerja dan devisa, pendorong pertumbuhan ekonomi sentra-sentra baru di wilayah sekitar perkebunan karet maupun pelestarian lingkungan dan sumberdaya hayati. Namun sebagai negara produsen dengan luas areal terbesar dan produksi kedua terbesar dunia, Indonesia masih menghadapi beberapa kendala, yaitu rendahnya produktivitas, terutama karet rakyat yang merupakan mayoritas (91\%) areal karet nasional dan ragam produk olahan yang masih terbatas, yang didominasi oleh karet remah (crumb rubber) (Ditjen Bina Produksi Perkebunan, 2004).

Propinsi Sumatera Selatan adalah salah satu propinsi yang memiliki luas perkebunan karet terbesar di Indonesia, sehingga merupakan penyumbang devisa bagi pemerintah untuk ekspor karet di Indonesia. Perkebunan karet di Sumatera Selatan, sebagian besar didominasi oleh perkebunan karet rakyat 
yaitu sebesar 90\%. Demikian pula dengan produksi yang dihasilkan, perkebunan rakyat masih lebih dominan dibandingkan dengan perkebunan besar, baik milik Negara maupun swasta (Dinas Perkebunan Propinsi Sumsel 2004). Lahan areal perkebunan karet Sumatera Selatan dari tahun ke tahun mengalami peningkatan dan diikuti dengan jumlah produksi yang meningkat pula.

Namun demikian, tanaman Karet yang tua atau rusak pada perkebunan karet rakyat di Kabupaten Musi Rawas mencapai 50.823 hektar atau 10,65 persen dari total luas areal, dengan produktivitas 0,79 ton/ha/thn. Peremajaan untuk tanaman perkebunan karet ini perlu mendapat prioritas utama dengan pertimbangan sebagai berikut : a) Pada setiap tahun terdapat tanaman menghasilkan yang akan memasuki masa non produktif, sehingga apabila tidak segera dilakukan peremajaan maka areal karet tua atau non produktif akan semakin luas; dan b) peremajaan karet tua dengan menggunakan klon unggul baru akan memberikan dampak peningkatan produksi dan pendapatan petani yang nyata di masa mendatang.

Salah satu usaha peningkatan produksi tanaman karet di Indonesia dilakukan melalui upaya peremajaan dan perluasan areal. Usaha itu perlu dilakukan dengan kenyataan bahwa produksi karet rakyat masih rendah sebagai akibat bahan tanaman yang digunakan bukan hasil okulasi klon unggul, kurangnya pemeliharaan dan penyadapan yang kurang baik. (Amypalupy, 1999).

Dalam pengembangan perkebunan karet rakyat, berbagai masalah yang dihadapi komplek. Luas areal karet secara alami terus meningkat, namun demikian sebagian besar petani masih menerapkan pola tradisional yaitu menanam tanaman karet yang tidak diketahui asal usul klonnya dengan jelas dan pemeliharaan hanya dilakukan pada waktu masih tanaman sela. Sejalan dengan pesatnya perkembangan proyek karet rakyat, petani karet rakyat di Sumatera Selatan umumnya dan di Kabupaten Musi Rawas khususnya telah mulai mengadopsi bibit unggul. Adopsi bahan tanaman unggul biasanya diikuti dengan adopsi teknologi seperti jarak tanam, lubang tanam, dan pembentukan cabang. Pesatnya penanaman karet oleh petani juga didorong semakin membaiknya harga karet dan harga komoditi lain yang tidak stabil. Permasalahannya apakah dengan cara seperti ini pendapatan petani di Kabupaten Musi Rawas dapat di tingkatkan. Tidak hanya bibit unggul dan harga yang membaik yang menjadi perhatian dalam pengembangan perkebunan karet rakyat sehingga pendapatan petani dapat ditingkatkan, juga ada beberapa faktor lain.

Pengetahuan petani akan inovasi baru akan mudah diserap seperti dengan menggunakan bibit unggul, produksi akan meningkat dan lebih cepat berproduksi. Pada penggunaan bukan bibit unggul serta kayu yang dihasilkan juga memiliki mutu yang lebih baik. Sumber dana petani untuk melakukan peremajaan perkebunan karet berasal dari pendapatan usahatani karet, usahatani bukan karet dan di luar pertanian. 
Permasalahannya adalah bagaimana potensi modal petani karet dalam melakukan peremajaan karet?. Apakah jumlah pendapatan total yang dikurangi dengan seluruh pengeluaran keluarga petani yang dimiliki mampu secara efektif digunakan dalam peremajaan perkebunan karet. Apakah ada kerjasama baik dari pemerintah maupun swasta dalam menanggulangi masalah dana dalam peremajaan. Belum adanya kerjasama yang baik dari pemerintah maupun swasta dalam membantu petani karet melakukan peremajaan, sehingga untuk mengatasi dana tersebut petani hanya mengandalkan pendapatan dari usahatani karet dan usahatani bukan karet di luar pertanian untuk disimpan.

Berdasarkan keadaan tersebut di atas maka tujuan penelitian ini adalah untuk menghitung besarnya potensi modal yang dimiliki petani dalam melakukan peremajaan karet.

\section{METODE PENELITIAN}

\section{Lokasi dan Waktu Penelitian}

Metode penelitian yang digunakan dalam penelitian ini adalah metode survei dengan harapan dapat memperoleh gambaran yang jelas di lapangan. Metode purposive digunakan karena di Kabupaten Musi Rawas Kecamatan Muara Beliti merupakan daerah dengan populasi petani karet terbesar. Dari Kecamatan tersebut dipilih Kelurahan yang akan dijadikan contoh.

Mengingat besarnya populasi dan luasnya areal maka survey dilakukan terhadap populasi petani yang mempunyai karet tua atau rusak. Dari populasi tersebut ditentukan jumlah sampel yang diambil sebanyak 60 KK sebagai responden. Petani karet yang akan dijadikan contoh harus memenuhi kriteria sebagai berikut: petani pemilik dan pengarap; memiliki tanaman tua; dan karet merupakan sumber pendapatan utama.

\section{Jenis dan Sumber Data}

Pengumpulan data di lapangan dilakukan melalui wawancara langsung dengan petani contoh dengan menggunakan daftar pertanyaan (Questionnaire). Data yang dikumpulkan meliputi data primer dan data sekunder. Data primer meliputi identitas petani responden, luas lahan yang diusahakan, pendidikan, produksi, biaya produksi, penerimaan, pendapatan, pengeluaran rumah tangga dan lain-lain. Data sekunder di dapat dari lembaga dan instansi yang berkaitan dengan penelitian, yaitu Camat Muara Beliti, Dinas Perkebunan Kabupaten Musi Rawas dan Kantor Statistik Musi Rawas.

\section{Pengolahan dan Analisis Data}

Analisis data menggunakan Program Linier merupakansalahsatuteknik yang digunakan paling luas dan diketahui dengan baik. Ia merupakan metode matematik dalam mengalokasikan sumberdaya yang langka untuk mencapai tujuan tunggal seperti mengoptimumkan biaya. Program Linier sebagai suatu 
model matematik yang terdiri atas sebuah fungsi tujuan linier dan sistem kendala linier. Maka pada tujuan ketiga adalah untuk menghasilkan luas lahan optimum agar mendapat pendapatan yang terus menerus. Tiga variabel dalam masalah ini adalah: Jumlah luas lahan karet, Jumlah Luas lahan selain karet, pendapatan total petani. Sedangkan permasalahan untuk mengoptimumkan luas lahan karet dapat dirumuskan sebagai berikut.

\section{Variabel Keputusan}

Masalah untuk mengoptimumkan luas lahan karet ada tiga variabel: yaitu luas lahan masing-masing tanaman, luas lahan ini dilambangkan dengan:

$\mathrm{X}_{1}=$ Luas lahan Karet yang diremajakan (ha); $\mathrm{X}_{2}=$ Luas Lahan yang tidak untuk diremajakan atau sumber pendapatan petani (ha) $X_{3}=$ Luas Lahan untuk tanaman pangan (ha); $\mathrm{X}_{4}=$ Luas Lahan untuk perkebunan Selain karet (ha)

\section{Fungsi Tujuan}

Tujuan petani adalah mengoptimumkan luas lahan yang untuk diremajakan, sehingga fungsi tujuan yang mencerminkan keuntungan yang diperoleh dari melakukan peremajaan dituliskan sebagai berikut:

$Z=A_{1} X_{1}+B_{1} X_{2}+C_{1} X_{3}+D_{1} X_{4}$

Dimana :

$\mathrm{A}_{1} \mathrm{X}_{1}$ : Luas lahan untuk diremajakan; $\mathrm{B}_{1} \mathrm{X}_{2}$ : Modal untuk luas lahan yang tidak untuk diremajakan; $\mathrm{C}_{1} \mathrm{X}_{3}$ : Tenaga kerja untuk luas lahan tanaman pangan; $\mathrm{D}_{1}$ $\mathrm{X}_{4}$ : Tabungan untuk perkebunan selain karet

\section{Fungsi Kendala}

Kendala petani dalam melakukan peremajaan adalah luas lahan untuk diremajakan, luas lahan, Modal dan tenaga kerja, kendala ini dilambangkan dengan :
a. Lahan
$: a_{1} X_{1}+a_{2} X_{2}+a_{3} X_{3}+a_{4} X_{4} \leq A$
b. Modal
$: b_{1} X_{1}+b_{2} X_{2}+b_{3} X_{3}+b_{4} X_{4} \leq M$
c. TenagaKerja
$: c_{1} X_{1}+c_{2} X_{2}+c_{3} X_{3}+c_{4} X_{4} \leq T K$
d. Tabungan
$: \mathrm{d}_{1} \mathrm{X}_{1}+\mathrm{d}_{2} \mathrm{X}_{2}+\mathrm{d}_{3} \mathrm{X}_{3}+\mathrm{d}_{4} \mathrm{X}_{4} \leq \mathrm{T}$

Dimana :

$\mathrm{a}_{1}-\mathrm{a}_{4}$ : Lahan; $\mathrm{b}_{1}-\mathrm{b}_{4}:$ Modal; $\mathrm{c}_{1}-\mathrm{c}_{4}$ : Tenaga Kerja; $\mathrm{d}_{1}-\mathrm{d}_{4}$ : Tabungan

\section{HASIL DAN PEMBAHASAN}

\section{Potensi Modal Petani}

Potensi modal petani adalah pendapatan total petani dikurang dengan jumlah konsumsi rumah tangga, dan bagian pendapatan itu yang bisa dijadikan potensi modal petani untuk melakukan peremajaan walaupun tidak semua pendapatan tersebut digunakan sebagai modal untuk melakukan peremajaan 
karet. Rata-rata potensi modal petani di Kecamatan Muara Beliti dapat di lihat pada Tabel 1

Tabel 1. Rata-rata potensi modal petani untuk peremajaan di Kecamatan Muara Beliti, 2008 (kk/tahun)

\begin{tabular}{ccc}
\hline No & Desa/ Kelurahan & $\begin{array}{c}\text { Potensi Modal } \\
(\mathrm{Rp} / \mathrm{kk} / \mathrm{thn})\end{array}$ \\
\hline 1. & Pasar Muara Beliti & 3.759 .100 \\
2. & Muara Beliti Baru & 2.252 .600 \\
3. & Pedang & 1.431 .650 \\
\hline & Rata-rata & 2.481 .350 \\
\hline
\end{tabular}

Hasil di lapangan menunjukkan rata-rata potensi modal yang dimiliki petani di Kecamatan Muara Beliti yaitu sebesar Rp. 2.481.350,- per tahun . Sedangkan menurut Balai Penelitian di Sumbawa Kabupaten Musi Banyuasin total biaya untuk meremajakan tanaman karet untuk tahun pertama sebesar Rp. 5.175.000,- per hektar dapat dilihat pada Tabel 2.

Tabel 2. Biaya Peremajaan Karet per hektar tahun 0 sampai tahun ke 5

\begin{tabular}{cc}
\hline Tahun & Biaya Peremajaan \\
\hline Tahun 0 & 5.175 .000 \\
Tahun 1 & 2.390 .000 \\
Tahun 2 & 1.635 .000 \\
Tahun 3 & 1.730 .000 \\
Tahun 4 & 1.580 .000 \\
Tahun 5 & 1.980 .000 \\
\hline Total & 14.490 .000 \\
\hline
\end{tabular}

Sumber : Balai Penelitian Sumbawa, Kabupaten Musi Banyuasin, 2008

Potensi modal yang dimiliki petani apabila dikaitkan dengan kebutuhan petani untuk karet untuk tahun pertama masih kurang sekitar Rp. 2.693.350,per hektar, maka petani berusaha untuk mencari pendapatan lain dengan cara menjual kayu karet tua. Dari penjualan kayu karet tua maka akan diperoleh pendapatan sebesar Rp. 5.000.000,- setelah dikurangi ongkos tebang dan alat angkut. Jadi potensi modal petani untuk peremajaan karet menjadi Rp. 7.693.650. Sedangkan biaya untuk peremajaan karet untuk setiap hektar dari tahun 0 ke tahun 5 sebesar Rp. 14.490.000,- dengan demikian petani hanya memiliki potensi modal sebesar 52 persen dari total biaya peremajaan atau setengah dari biaya kebutuhan peremajaan.

Alternatif lain apabila kayu karet tidak terjual maka petani bisa menggunakan tabungan petani seperti perhiasan, barang berharga lain sebagai potensi modal untuk peremajaan karet. Potensi modal lain juga bisa didapat dengan pinjaman modal dari pemerintah dengan cara pinjaman kredit yang 
akan dikembalikan bila tanaman karet sudah menghasilkan. Pendapatan tambahan juga bisa didapat apabila seluruh luas lahan karet sudah diremajakan, petani bisa membuka usaha dengan cara melakukan pembibitan karet yang hasilnya bisa dijual dan juga bisa dipergunakan untuk peremajaan karet petani itu sendiri.

Rata-rata luas lahan karet petani yang harus diremajakan adalah 1,86 hektar maka biaya yang dibutuhkan untuk meremajakan karet seluas 1,7 hektar dari tahun 0 sampai tahun ke 5 sebesar Rp. 24.633.000,-. Sedangkan potensi modal yang dimliki petani sebesar Rp. 7.693.650,- jadi dengan kenyataan diatas maka petani memiliki potensi modal sebesar 30 persen dari total biaya peremajaan yang dibutuhkan.

Upaya petani untuk bisa meremajakan karetnya dengan cara meremajakan karetnya secara bertahap. Dari total luas lahan yang akan diremajakan 1,7 hektar petani meremajakan 1 hektar terlebih dahulu, biaya yang dibutuhkan untuk tahun 0 sampai tahun ke 5 sebesar Rp. 14.490.000,- jadi dari total potensi modal yang dimiliki petani sebesar Rp. 7.693.650,- atau sebesar 52 persen. Salah satu cara untuk mendapatkan tambahan modal biasanya petani akan mencari pendapatan dengan cara mengusahakan tanaman sela tanaman karet yang masih produktif yang dapat mencukupi kebutuhan keluarga mereka.

Hasil penelitian di lapangan diketahui bahwa potensi modal dalam peremajaan karet masih kurang hal ini disebabkan masih banyaknya kebutuhan keluarga petani, seperti untuk biaya pendidikan sekolah anak petani. Oleh karena itu, sebaiknya upaya petani dalam meremajakan karet dilakukan dengan cara bertahap. Dari luas lahan karet yang dimiliki sebaiknya hanya sebagian dulu diremajakan, sehingga petani masih bisa menghasilkan pendapatan sebelum karet yang diremajakan sampai dengan berproduksi.

\section{Luas Lahan Optimum Untuk Diremajakan Dalam Rangka Memperoleh Pendapatan Kontinyu}

Petani karet yang belum meremajakan tanaman karetnya di Kecamatan Muara Beliti rata-rata memiliki lahan 1,86 hektar. Lahan tersebut selama ini dimanfaatkan untuk tanaman karet, kopi, cabe merah dan wortel. Dalam kegiatan usahatani untuk ke empat komoditas tersebut, dikerjakan oleh tenaga kerja dalam keluarga. Rata-rata tenaga kerja yang tersedia dalam setiap rumah tangga yaitu dua orang, sehingga untuk satu tahun tersedia tenaga kerja untuk kegiatan usahatani sebesar $592 \mathrm{HOK}$.

Disamping itu, untuk mengerakkan kegiatan usahatani tersedia modal rata-rata setiap keluarga yaitu Rp. 2.481 .350 berasal dari selisih pendapatan dengan pengeluaran keluarga selama setahun dan sebesar Rp.5.000,000,- berasal dari potensi penjualan kayu karet per hektar. Rata-rata penggunaan tenaga kerja, biaya produksi dan pendapatan dari empat macam jenis tanaman di lokasi penelitian disajikan pada Tabel 3. 
Tabel 3. Kebutuhan tenaga kerja, biaya produksi dan pendapatan dari tanaman di lokasi penelitian

\begin{tabular}{llccrrr}
\hline No & $\begin{array}{c}\text { Komponen } \\
\text { Input-output }\end{array}$ & $\begin{array}{c}\text { Karet } \\
\text { peremajaan }\end{array}$ & Kopi & $\begin{array}{c}\text { Cabe } \\
\text { Merah }\end{array}$ & Sayuran & $\begin{array}{c}\text { Karet } \\
\text { Tua }\end{array}$ \\
\hline 1 & $\begin{array}{l}\text { Tenaga kerja } \\
\text { (HOK/thn/ha) }\end{array}$ & 428 & 115 & 88 & 100 & 211 \\
2 & $\begin{array}{l}\text { Biaya Produksi } \\
\text { (Rp.000/thn/ha) }\end{array}$ & 3.984 & 2.905 & 2.929 & 3.150 & 2.959 \\
3 & $\begin{array}{l}\text { Pendapatan } \\
\text { (Rp.000/thn/ha) }\end{array}$ & 50.139 & 4.693 & 2.320 & 1.130 & 7.997 \\
\hline
\end{tabular}

Berdasarkan data kondisi usahatani karet dan tanaman lain yang diusahakan petani di lokasi penelitian dan ketersediaan sumberdaya lahan, modal dan tenaga kerja, maka dapat dirumuskan model optimasi untuk penentuan pemanfaatan lahan untuk peremajaan karet dan tanaman lain dengan menggunakan model Linear Programming sebagai berikut.

1. Variabel keputusan
a. X1 adalah luas lahan untuk peremajaan karet (ha)
b. X2 adalah luas lahan untuk tanaman kopi (ha)
c. X3 adalah luas lahan untuk tanaman cabe merah (ha)
d. X4 adalah luas lahan untuk sayuran (ha)
e. X5 adalah luas lahan untuk karet tua (ha)

2. Fungsi Tujuan: memaksimumkan keuntungan/ pendapatan rumah tangga petani

$$
\text { Max. } Z=50.139 X 1+4.693 X 2+2.230 X 3+1.130 X 4+7.997 X 5
$$

3. Fungsi kendala :

a. Kendala lahan (ha)

$$
\mathrm{X} 1+\mathrm{X} 2+\mathrm{X} 3+\mathrm{X} 4+\mathrm{X} 5 \leq 2
$$

b. Kendala modal (Rpjuta/tahun)

$3.984 X 1+2.905 \times 2+2.929 \times 3+3.150 \times 4+2.959 \times 5 \leq 7.481$

c. Kendala Tenaga Kerja (HOK/tahun)

$428 X 1+115 X 2+88 X 3+100 X 4+211 X 5 \leq 592$ 
Tabel 4. Hasil pengolahan data dengan menggunakan Linier Programming dari luas lahan yang dimiliki petani di Kecamatan Muara Beliti

\begin{tabular}{llll}
\hline No & Variabel & Value & Cost \\
\hline 1 & X1 (karet diremajakan) & 1.383 & 0.000 \\
2 & X2 (kopi) & 0.000 & 8.779 \\
3 & X3 (cabe merah) & 0.000 & 8.079 \\
4 & X4 (wortel) & 0.000 & 10.585 \\
5 & X5 (karet tua) & 0.000 & 16.721 \\
\hline
\end{tabular}

Hasil optimasi model Linear Programming pemanfaatan lahan untuk peremajaan karet dengan menggunakan bantuan program komputer ABQM merekomendasikan bahwa dengan luas lahan yang tersedia 2 hektar maka hanya satu jenis tanaman yang sebaiknya diusahakan yaitu karet untuk diremajakan seluas 1.38 ha. Sedangkan tanaman kopi, sayuran dan cabe merah tidak direkomendasikan untuk diusahakan. Dengan peremajaan karet tersebut akan menghasilkan pendapatan sebesar Rp. 69.351.000/ tahun.

\section{SIMPULAN DAN SARAN}

Berdasarkan hasil penelitian yang telah dilaksanakan maka dapat ditarik kesimpulan sebagai berikut :

1. Potensi modal yang dimiliki rata-rata adalah sebesar Rp. 2.481.650 dan ditambah dengan pendapatan dari menjual kayu karet tua sebesar Rp. 5.000.000 maka petani memiliki potensi modal sebesar Rp. 7.481.650,-. Dari potensi modal petani tersebut ternyata baru mampu membiayai 52 persen dari total biaya peremajaan pertahun.

2. Luas lahan yang optimum untuk diremajakan adalah sebesar 1,383 hektar dengan pendapatan sebesar Rp. 69.351.000,- sedangkan sumber daya yang langka adalah tenaga kerja, setiap penambahan satu satuan HOK akan memberikan pendapatan sebesar Rp. 117.000

Mengingat kondisi tersebut di atas maka dapat disarankan:

1. Sebaiknya petani mengalokasikan pendapatan yang diperoleh untuk kebutuhan pemeliharaan karet terutama pada tanaman yang diremajakan

2. Perlunya peran pemerintah Daerah Kabupaten Musi Rawas yang aktif untuk memotivasi petani karet dalam melakukan kegiatan peremajaan karet selain itu perlu adanya pinjaman modal bagi petani karet untuk melakukan peremajaan karet, dan perlunya petani membuatkan sertifikat lahan kebunpetani sehingga memudahkan bagi petani untuk mendapatkan pinjaman modal dari pihak pemerintah. 


\section{DAFTAR PUSTAKA}

Balai Informasi Pertanian Sumatera Selatan. 1987. Budidaya Tanaman Karet. Departemen Pertanian.

Dinas Perkebunan Provinsi Sumatera Selatan. 2004. Arah Kebijakan Jangka Panjang Pembangunan Perkebunan Sumatera Selatan. Palembang.

Setyamidjaja, Djoehana. 1999. Karet Budidaya dan Pengolahan. Kanisius, Yogyakarta.

Tim Penulis Penebar Swadaya. 2004. Karet, Strategi Pemasaran, Budidaya dan Pengolahan. Penebar Swadaya. Jakarta.

Tim Penulis Penebar Swadaya. 1999. Karet, Strategi Pemasaran Tahun 2000, Budidaya dan Pengolahan. Penebar Swadaya. Jakarta.

Winardi. 1983. Harga dan Penetapan Harga dalam Bidang Pemasaran (Marketing). PT. Citra Aditya Bakti. Bandung. 